\title{
Retraction of: Novel, Small Molecule induced GABA-hATSCs for Targeting of Neuropathic Pain
}

Cubsequent to the publication of "Novel, Small Molecule induced GABA-hATSCs for Targeting of Neuropathic Pain" by Jee et. al. (online ahead of print March 2013; DOI: 10.1089/hum.2012.097) in Human Gene Therapy, we became aware of four papers that were retracted from Antioxidants and Redox Signaling from this same group (Im et al, 2012; Choi et al; 2012; Jang 2012a; Jang et al 2012b).

A routine analysis of the Human Gene Therapy paper for similarity to other previously published papers revealed a high degree of language identity with two of the retracted papers, including parts of the Results section. This raises concerns about the integrity of data within the Human Gene Therapy paper. The editorial leadership of Human Gene Therapy therefore has decided to retract the paper from Human Gene Therapy. The previously published retraction in Antioxidants and Redox Signaling indicates that officials from the institution where this research was conducted have initiated an investigation.

Human Gene Therapy is dedicated to upholding the strictest guidelines of scientific publishing and does not tolerate any impropriety.

\section{References}

Im, Y.B., et. al. Antioxid Redox Signal 2012;16:1046-1060. DOI: 10.1089/ars.2011.4224.

Choi JI, Jee MK, Im YB, Kang SK. Novel GSK-3b inhibitors and CBM-1078 guide hATSCs' deaging via Oct4 and b-catenin activation. Antioxid Redox Signal. 2012, [Epub ahead of print]; DOI: 10.1089/ars.2011.4422.

Jang JH, Jung JS, Choi JI, Kang SK. Nuclear Ago2/HSP60 contributes to broad spectrum of hATSCs function via Oct4 regulation. Antioxid Redox Signal 2012a;16:383-399.

Jang JH, Jung JS, Im YB, Kang KS, Choi JI, Kang SK. Crucial role of nuclear Ago2 for hUCB-MSCs differentiation and self-renewal via stemness control. Antioxid Redox Signal 2012b;16:95-111. 